\title{
Optical techniques for tracking multiple myeloma engraftment, growth, and response to therapy
}

\author{
Judith M. Runnels, ${ }^{a, b, c, *}$ Alicia L. Carlson, ${ }^{a, c, *}$ Costas Pitsillides, ${ }^{a}$ Brian Thompson, ${ }^{a}$ Juwell Wu, ${ }^{a}$ Joel A. Spencer, ${ }^{a}$ John M.

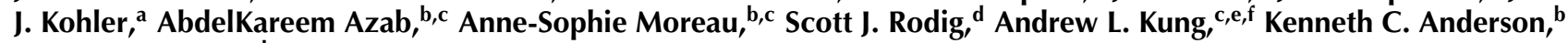 \\ Irene M. Ghobrial, ${ }^{b}$ and Charles P. Lina,c \\ a Massachusetts General Hospital, Wellman Center for Photomedicine and Center for Systems Biology, Advanced \\ Microscopy Program, Boston, Massachusetts 02114 \\ ${ }^{b}$ Dana-Farber Cancer Institute, Department of Medical Oncology, Boston, Massachusetts 02115 \\ ${ }^{\mathrm{c}}$ Harvard Medical School, Boston, Massachusetts 02115 \\ 'Brigham and Women's Hospital, Department of Pathology, Boston, Massachusetts 02115 \\ e Dana-Faber Cancer Institute, Department of Pediatric Oncology, Boston, Massachusetts 02115 \\ ${ }^{\mathrm{f} C}$ Children's Hospital, Department of Hematology/Oncology, Boston, Massachusetts 02115
}

\begin{abstract}
Multiple myeloma ( $\mathrm{MM})$, the second most common hematological malignancy, initiates from a single site and spreads via circulation to multiple sites in the bone marrow (BM). Methods to track MM cells both in the BM and circulation would be useful for developing new therapeutic strategies to target MM cell spread. We describe the use of complementary optical techniques to track human MM cells expressing both bioluminescent and fluorescent reporters in a mouse xenograft model. Long-term tumor growth and response to therapy are monitored using bioluminescence imaging (BLI), while numbers of circulating tumor cells are detected by in-vivo flow cytometry. Intravital microscopy is used to detect early seeding of MM cells to the BM, as well as residual cancer cells that remain in the BM after the bulk of the tumor is eradicated following drug treatment. Thus, intravital microscopy provides a powerful, albeit invasive, means to study cellular processes in vivo at the very early stage of the disease process and at the very late stage of therapeutic intervention when the tumor burden is too small to be detected by other imaging methods. @ 2011 Society of Photo-Optical Instrumentation Engineers (SPIE). [DOI: 10.1117/1.3520571]
\end{abstract}

Keywords: In vivo cell tracking; multiple myeloma; intravital imaging; in vivo flow cytometry; confocal microscopy; bioluminescence. Paper 10188SSR received Apr. 9, 2010; revised manuscript received Aug. 2, 2010; accepted for publication Aug. 4, 2010; published online Jan. 11, 2011.

\section{Introduction}

\subsection{Cancer Models for In-Vivo Imaging Studies}

In-vitro study of cancer cell lines has contributed tremendously to our understanding of the genetics and biochemistry of the malignant phenotype. In-vitro studies offer the advantage of a controlled environment, where one can design experiments to study one variable at a time. However, malignancies occur naturally in the complex environment of a living organism where many stimuli interact with cancer cells simultaneously. Growth of cancer cells in culture does not necessarily translate into tumor growth in vivo. The hospitable in-vivo environment for tumor cells includes appropriate cell signaling through external stimuli, access to nutrients and blood supply, and avoidance of the immune system. To study the myriad of interactions that a developing tumor undergoes requires the use of appropriate animal models that recapitulate key aspects of human tumors. Small rodents, in particular, are useful, as they have been genetically characterized, and strains with desirable genetic backgrounds have been developed to study tumor progression.

Traditionally, in-vivo experiments have been limited to looking at whether or not a tumor grows in a particular host, ${ }^{1}$ with-

*Eually contributing first authors.

Address all correspondence to: Charles P. Lin, Massachusetts General Hospital, Wellman Center for Photomedicine and Center for Systems Biology, Boston, Massachusetts 02114. Tel: 617-724-3957; Fax: 617-643-3669. E-mail: lin@helix.mgh.harvard.edu and Irene M. Ghobrial, Dana-Farber Cancer Institute, Department of Medical Oncology, Boston, Massachusetts 02115. Tel: 617-6324198; Fax: 617-632-9862. E-mail: irene_ghobrial@dfci.harvard.edu out being able to characterize specific interactions in the process. Typically, superficial tumor growth has been monitored by caliper measurement, while identifiable internal tumors have been assessed by a single end-point volume measurement. These experiments required sacrifice of the animal to detect, characterize, and quantify the tumor.

Bioluminescence imaging (BLI) is a noninvasive, quantitative method that enables longitudinal studies of the changes in tumor volume and response to treatment in an individual animal over time. BLI measures visible light that is emitted by luciferase-catalyzed reactions on the luciferin substrate in the presence of oxygen. ${ }^{2}$ It has been used to image the development of implanted tumors in mice ${ }^{3-7}$ and spontaneous tumors in transgenic mice, ${ }^{8}$ to assess the tumorigenicity of cell lines, ${ }^{9}$ and to monitor metastasis and response to chemotherapy. ${ }^{6,9}$

With BLI, the pattern of tumor spread can be followed in the same animal over time. However, BLI lacks the sensitivity and spatial resolution to examine events at the single cell level. Intravital microscopy (IVM), on the other hand, permits direct visualization of individual living cells and tissues with submicrometer resolution within an intact organism. Its capability is further enhanced by 3-D optical sectioning techniques such as confocal and multiphoton microscopy. Imaging of structures deeper than the surface of the skin requires surgical exposure to allow optical access due to the limited penetration depth of these imaging modalities, although advances in endoscopic

1083-3668/2011/16(1)/011006/13/\$25.00 @ 2011 SPIE 
microscopy allow minimally invasive imaging of internal organs through natural orifices or through small openings in the skin. ${ }^{10,11}$ Similarly, imaging of bone marrow has been difficult due to the thickness of the cortical bones, but can be done through the more translucent calvarial bone of the mouse skull. ${ }^{12}$

IVM has been used to study processes in cancer metastasis that were previously inaccessible by traditional in-vivo and in-vitro assays. Movement of cells within the tumor, the interaction of tumor cells with vascular endothelium, intra- and extravasation of tumor cells, their organ preference through local cytokine attraction, and tumor induction of angiogenesis have all been documented using IVM. ${ }^{13-16}$ Similar techniques have also been used to obtain insight into angiogenesis, blood flow, cell adhesion, and interstitial diffusion. ${ }^{17}$ Most of these studies require labeling of specific structures or cell populations with fluorescent probes or stably expressed fluorescent proteins to provide contrast. Fluorescent reporter proteins, such as green fluorescent protein (GFP), are passed on to daughter cells so that growth of the tumor can be documented, ${ }^{16,18}$ whereas fluorescent cytoplasmic and membrane dyes are diluted by cell proliferation and are best used in short-term studies.

\subsection{Multiple Myeloma}

Multiple myeloma (MM) manifests itself as a malignant proliferation of plasma cells, the terminally differentiated cells in the $\mathrm{B}$ cell lineage. It generally affects older individuals ${ }^{19}$ and occurs at a frequency of one in 25,000 individuals. ${ }^{20}$ Symptoms of the disease are a reflection of the biology of the affected cell type. Plasma cells are the antibody producing cells of the immune system. In MM, the malignant plasma cells are clonal and produce one immunoglobulin product, rather than an array of immunoglobulins with a range of specificities. As the disease progresses untreated, the increased number of malignant plasma cells results in the overproduction of immunoglobulin product and subsequent blood hyperviscosity, potential visual problems, and kidney failure. ${ }^{19}$ Furthermore, as the tumor outcompetes normal plasma cells, overproduction of the single MM immunoglobulin over the normal antibody array results in compromised immunity in the patient.

MM grows and spreads in the bone marrow (BM), the spongy hematopoietic (i.e., blood-forming) tissue inside bone cavities. Normally, fewer than $0.5 \%$ of BM cells are plasma cells. ${ }^{21}$ However, myeloma patients have greatly increased numbers of plasma cells, and usually present with multiple diffuse plasma cell tumors in the marrow of several bones. ${ }^{22}$ Since MM cells within a patient are clonal, the presence of multiple affected sites suggests that the MM cells metastasize to new distant marrow homes. ${ }^{23,24}$ Experimental xenograft models of human multiple myeloma exist that measure localized tumor progression (i.e., the SCID-hu and subcutaneous plasmacytoma models) ${ }^{25-27}$ as well as systemic diffuse bone marrow disease. Whole body imaging (GFP or bioluminescence) ${ }^{28,29}$ has been successfully used in both of these model systems.

Like some other malignant cell types ${ }^{30-32}$ and nonmalignant hematopoietic stem cells, ${ }^{33,34}$ it has been shown that MM cells rely on the surface protein CXCR4 to direct them to the source of the cytokine SDF-1 in the bone marrow. ${ }^{35,36}$ Binding of SDF-1 to CXCR4 on the surface of a circulating cell induces a cascade of events, including upregulation of integrin binding proteins. ${ }^{37}$
These events allow MM cells to roll and stick to the bone marrow endothelial surface, enabling the MM cells to exit through the endothelial layer into surrounding tissue. Once in the marrow, MM growth results in activation of the digestive processes normally involved in bone remodeling ${ }^{38-40}$ but without significant new bone synthesis, leading to lytic bone lesions around the tumor that can be detected by x-ray and that often result in fractures as the disease progresses. ${ }^{19}$ While the tumor is mostly confined to BM spaces, late in the disease process MM cells can be detected in the peripheral circulation, ${ }^{41}$ and soft tissue organs can be affected.

Recent advances in therapies, both directed toward the tumor cell and its interaction with the microenvironment, have extended patient life span. ${ }^{42,43}$ Instead of affecting the replication machinery of the cell, these new therapies work by different mechanisms, including inhibiting tumor-directed angiogenesis, inducing MM cell death through apoptosis, interfering with MM binding to bone marrow stromal cells (BMSC) and extracellular matrix proteins, inhibiting cytokine secretion by MM cells, stimulating an immune response, and/or altering transcription of the genome in the tumor cells. ${ }^{44-46}$ In addition, combining new drugs with older standard MM treatments has proven more effective than either single treatment alone. ${ }^{47}$

We use a xenograft mouse model together with BLI, IVM, and in-vivo flow cytometry (IVFC) to study tumor progression and regression following treatment with one of the new drugs, bortezomib. Bortezomib is a clinically approved agent that acts by interfering with the degradation of proteins by the $26 \mathrm{~S}$ proteasome complex within the cell. Protein degradation is a component of a complex regulatory network in cells that controls the cell cycle, DNA repair, growth arrest, and apoptosis. ${ }^{48,49}$ Because cancer cells produce defective proteins at a higher rate than normal cells, they are more dependent on the proteosome to remove these toxic products, and subsequently are more sensitive to blockage of the proteosome complex than normal cells. ${ }^{48-52}$ Blockage of protein degradation ultimately results in cell death through apoptosis. ${ }^{51,52}$

\section{Materials and Methods}

\subsection{Animals}

Animal studies were conducted under the approval and guidelines of the Dana-Farber Cancer Institute (DFCI) and Massachusetts General Hospital (MGH) Institutional Animal Care and Use Committees. Young nonirradiated male SCID beige (SCID/Bg) and female BALB/c mice were obtained from Charles River Laboratories (Wilmington, Massachusetts). Col2.3GFP mice ${ }^{53}$ were used to demonstrate in-vivo homing and engraftment of MM cells with respect to localization of $\mathrm{BM}$ osteoblast lineage cells, and were kindly provided by Rowe at the University of Connecticut and maintained by LoCelso at MGH, Boston, Massachusetts. To better approximate physiological conditions under which multiple myeloma normally grows, we used mice that had not been irradiated throughout these experiments.

Anesthesia was performed by intraperitoneal injections of a ketamine (Bedford, Laboratory, Bedford, Ohio)/xylazine (Lloyd Laboratories, Shenandoah, Iowa) cocktail at $80-\mathrm{mg} / \mathrm{kg} / 12-\mathrm{mg} /$ $\mathrm{kg}$ body weight. Mice were sacrificed by cervical dislocation while under anesthesia after the appropriate imaging session. 


\subsection{Cells}

MM.1S cells ${ }^{54}$ were the kind gift of Rosen at Northwestern University. This cell line was genetically modified to carry GFP, firefly luciferase, and neomycin genes (MM.1S-GFP-Luc-neo cells). ${ }^{36}$ Primary MM cells were obtained from bone marrow samples from patients with the use of CD138 microbead selection (Miltenyl Biotec, Auburn, California). Informed consent was obtained from all patients in accordance with the Declaration of Helsinki. Approval of these studies was obtained by the Dana-Farber Cancer Institute Institutional Review Board.

\subsection{Anti-VLA 4 treatment}

MM.1S were reacted with mouse antihuman CD49d (clone HP2/1, AbD Serotec, Raleigh, North Carolina) according to the manufacturer's recommendation before the cells were injected into mice to quantify circulating cells. This antibody binds to the $\alpha$ subunit of the very late antigen (VLA) 4 integrin.

\subsection{Bortezomib treatment}

Mice carrying MM tumors were treated with $1-\mathrm{mg} / \mathrm{kg}$ bortezomib (PS-341, Millennium Pharmceuticals, Incorporated, Cambridge, Massachusetts) twice weekly beginning at the indicated time. Bortezomib was suspended in phosphate buffered saline at $1-\mathrm{mM}$ concentration, and the mice were injected intraperitoneally.

\subsection{DiD/DiO Cell Labeling}

MM.1S cells were labeled for $30 \mathrm{~min}$ at $37^{\circ} \mathrm{C}$ with $1 \mu \mathrm{M}$ of the lipophilic cyanine dyes, DiD or DiO (Vibrant DiD or DiO, Molecular Probes, InVitrogen, Eugene, Oregon) in RPMI with $0.1 \%$ bovine serum albumen (BSA) according to the manufacturer's recommendations and as previously described. ${ }^{35}$ The cells were injected into mice through the tail veins. The mice were then either subjected immediately to in-vivo flow cytometry, or they were imaged immediately or within a few days to capture the membrane dyes' fluorescence before dilution through cell division.

\subsection{Imaging Reagents}

For delineating the vasculature in imaging experiments, mice were injected intravenously with either $2-\mathrm{ng} / 0.1 \mathrm{ml}$ Angiosense750 (VisEn Medical, Woburn, Massachusetts) or $0.1 \mathrm{ml}$ of 0.67- $\mu$ M Qtracker nontargeted Quantum Dots 800 (Molecular Probes, InVitrogen, Carlsbad, California), depending on the specific experiment, as indicated by the manufacturer's directions. The endosteal surface was labeled in some experiments with the fluorescent bisphosphonate Osteosense 750 (VisEn Medical, Woburn, Massachusetts) according to the manufacturer's recommendation.

\subsection{In-Vivo Flow Cytometry}

In-vivo flow cytometry is a new technology that allows realtime, continuous monitoring of fluorescent cells in the circulation of live animals without the need to draw blood samples. ${ }^{55}$ In these experiments, mice were anesthetized, 2 to $3 \times 10^{6}$ cells were injected intravenously, and then the mouse was positioned on a temperature-controlled stage $\left(32^{\circ} \mathrm{C}\right)$. An appropriate arteriole in the ear was then chosen for obtaining measurements. The GFP or DiO fluorescence of circulating cells was excited by a 473-nm diode-pumped solid-state laser (85 BCA 015, Melles Griot, Carlsbad, California) focused as a slit across the ear vessel. Signal was detected by a photomultiplier tube (R3896 with socket C6271, Hamamatsu Corporation, Bridgewater, New Jersey), through a $525+/-25-$ nm bandpass filter (BP525/50, Chroma Technologies, Rockingham, Vermont), and then digitized for analysis on a personal computer equipped with Matlab software (The MathWorks, Natick, Massachusetts). Likewise, fluorescence from DiD-labeled cells was excited with a 633-nm HeNe laser (1144/P, JDS Uniphase, Milpitas, California) and detected through a $670+/-20$-nm filter (XF3030 670DF40, Omega Optical, Brattleboro, Vermont).

\subsection{Bioluminescence Imaging}

Mice were intraperitoneally injected with $75-\mathrm{mg} / \mathrm{kg}$ luciferin (Xenogen, Hopkinton, Massachusetts) and imaged for bioluminescence $10 \mathrm{~min}$ after the injection. The noncommercial bioluminescence system used an electron multiplying CCD camera (E2V TECH CCD87, Andor Technology, Belfast, United Kingdom) with an exposure time of $15 \mathrm{~s}$, an electron multiplication gain of $600,5 \times 5$ binning, and background subtraction. Images were analyzed with ImageJ software, version 1.38 (National Institutes of Health, Bethesda, Maryland, open source at http://rsb.info.nih.gov/ij/index.html).

\subsection{In-Vivo Video Rate Confocal and Multiphoton Microscopy}

MM cell growth in the bone marrow of calvarial bones was analyzed using fluorescence confocal microscopy, as previously described. ${ }^{30}$ Briefly, skin flaps are made in the scalps of the mice to expose the underlying dorsal skull surfaces. Images of the tumors or individual tumor cells were captured in approximately 2 to 3 -h long sessions. High-resolution images with cellular detail were obtained through intact mouse skulls at depths of up to $200 \mu \mathrm{m}$ from the skull surfaces using a $30 \times 0.9-N A$ water immersion objective lens (Lomo, Saint Petersburg, Russia), which corresponded to a field of view of $660 \times 660 \mu \mathrm{m}$. Blood vessels were imaged using blood pool agents, Angiosense-750 (VisEn Medical, Woburn, Massachusetts) or Qtracker nontargeted Quantum Dots 800 (Molecular Probes, Invitrogen, Carlsbad, California). Angiosense-750 was excited with a 735-nm diode laser (Melles Griot, Carlsbad, California), and the fluorescence intensity was captured by a photomultiplier tube (PMT) (R3896 with socket C7950, Hamamatsu Corporation, Bridgewater, New Jersey) detector after passing through a 770-nm long-pass filter (HQ770LP, Chroma Technologies, Rockingham, Vermont). GFP was excited with a 491-nm solid-state laser (Dual Calypso 20, Cobolt AB, Stockholm, Sweden) and detected with a PMT through a 528+/ - 19-nm bandpass filter (FF01-528/38-25, Semrock, Rochester, New York). Both DiD labeled cells and Qtracker nontargeted Quantum Dots 800 (Invitrogen, Carlsbad, California) were excited with a $635 \mathrm{~nm}$ helium-neon laser (Radius, Coherent Incorporated, Santa Clara, California) and detected 
through a $695+/-27.5-\mathrm{nm}$ bandpass filter (XF3076 695AF55, Omega Optical, Brattleboro, Vermont) or 770-nm longpass filter (HQ770LP, Chroma Technologies, Rockingham, Vermont), respectively. Images of the bone were acquired through a 370 + / - 18-nm bandpass filter (FF01-370/36-25, Semrock, Rochester, New York) using second harmonic generation (SHG) imaging at 775-nm excitation (Mai Tai HP, Spectra-Physics, Irvine, California). The optical section thickness of the confocal microscope, as measured by translating a mirror through the focus of the microscope and calculating the corresponding fullwidth at half-maximum signal intensity, is $12 \mu \mathrm{m}$ at $491 \mathrm{~nm}$ and $24 \mu \mathrm{m}$ at $635 \mathrm{~nm}$. The nominal section thickness of the SHG images is calculated to be $1.4 \mu \mathrm{m}$.

Similarly, imaging of Col2.3 mice, as shown in Fig. 1, was done with two-photon and second harmonic generation microscopy, as previously described. ${ }^{56}$ High-resolution images with cellular detail were obtained through the intact mouse skull using a $30 \times 0.9-N A$ water immersion objective lens (Lomo, Saint Petersburg, Russia), which corresponded to a field of view of $330 \times 330 \mu \mathrm{m}$ on this instrument. All images were acquired using 840-nm excitation (Mai Tai HP, Spectra-Physics, Irvine, California). Images of bone were acquired using second harmonic generation imaging of the scattering signature from the bone through a $457+/-25-n m$ bandpass filter (FF01457/50-25, Semrock, Rochester, New York). GFP-expressing osteoblasts were imaged by two-photon microscopy, detecting the fluorescence through a $545+/-37.5-\mathrm{nm}$ bandpass filter (XF3105 545AF75, Omega Optical, Brattleboro, Vermont). Circulating quantum dots (Qtracker 655) were also imaged by twophoton microscopy through a $710+/-50-\mathrm{nm}$ bandpass filter (HQ710/100M, Chroma Technologies, Rockingham, Vermont).

Multiple sequential imaging depths were acquired at $10-\mu \mathrm{m}$ intervals, except for distance determination experiments. In those cases, $2-\mu \mathrm{m}$ sequential $z$-axis stacks were made. The frame rate of the confocal microscope was 30 frames per second. Images were captured, after averaging 30 frames, using a Macintosh computer equipped with an Active Silicon snapper card (CBL-25D-SNP, Active Silicon, Chelmsford, Massachusetts). Time points were taken at days 0,1 , and 3 after MM cell injection, then twice weekly beginning at 4 days after cell injection for the first two weeks, and finally followed by weekly imaging sessions.

\subsection{Image Processing and Three-Dimensional Distance Determinations}

Each channel was acquired individually, but simultaneously, in 8-bit grayscale and merged to form an RGB image using customdeveloped software (iPhoton). To measure cavity distances from the bone surface (Fig. 1), multiple image stacks from the same bone cavity were concatenated based on coordinate information. We assumed a refractive index of bone close to that of water (1.33) for the purposes of determining the axial location of the optical section. The refractive index of osteones isolated from the femoral diaphyses of oxen was estimated by Ascenzi and Fabry ${ }^{57}$ at various stages of mineralization to range from 1.555 to 1.564 . Thus, the refractive index mismatch at the interface between the immersion fluid and the bone will cause a slight axial displacement of the focus away from the bone surface. However, this effect should be somewhat mitigated by the curvature of the calvarial bone. Therefore, we assumed that the curved surface of the bone compensated for the increased index of refraction of the bone, and used an index of refraction of 1.33 for bone for the purpose of determining the axial location of each image in the image stack.

The image stack was imported into ImageJ (NIH, Bethesda, Maryland), resliced into the vertical planes $(y-z, x-z)$, and if necessary, digitally rotated to remove tilt resulting from positioning of the animal relative to the imaging plane. The RGB channels were separated. The grayscale intensity profile along the $z$-direction of the bone was measured and an exponential decay curve was fit to the data as a function of depth. The inverse of the calculated exponential decay was then multiplied to the bone (blue) channel to correct for the decrease in signal due to increased tissue absorption and scattering with depth. A similar function was applied to the osteoblast (green) and the vascular (red) channels using an empirically derived exponent. A multiplicative constant was incorporated to normalize the intensity between the channels. 3-D Euclidean distance measurements (Fig. 2) between MM cells and the endosteum, vasculature, and osteoblasts were performed using ImageJ after reslicing the $z$ stacks in the vertical planes.

\subsection{In-Vivo Homing Imaging Experiments}

Col2.3 mice were injected with $1 \times 10^{5}$ DiD labeled MM.1S cells. The mice were imaged between 2 to 6, 24, and 72-h post$\mathrm{MM}$ cell injection. Each mouse was used twice for imaging so that specific BM regions could be followed temporally. After the first imaging session, the scalp was sutured, treated with CVS (Consumer Value Stores) Pharmacy brand triple antibiotic salve, and allowed to recover.

\subsection{Long-Term Tumor Growth Experiments}

SCID/Bg mice were injected with $5 \times 10^{6}$ MM.1S-GFP-Luc-neo cells intravenously through the tail vein. Subsets of the mice were imaged twice weekly for the first two weeks, and weekly thereafter. Each mouse was sacrificed after the imaging session.

\subsection{Immunohistochemistry}

Mice used for long-term MM growth were sacrificed immediately after imaging. Skulls and femurs were extracted and submitted to the Specialized Histopathology Core Laboratory of the Dana-Farber/Harvard Cancer Center for confirmation of the in-vivo results. The calvarial bones and femurs were dissected and preserved in $10 \%$ formalin. The bones were decalcified using Kristensen's solution and then processed according to standard pathologic procedures. The following antibodies were used for immunohistochemical staining (antibody dilution, antibody clone, manufacturer): mouse antihuman CD38 (1:300, SPC32, Abcam, Cambridge, Massachusetts), mouse antihuman CD138 (1:50, MI-13, DAKO, Carpinteria, California).

Antigen retrieval was performed on $4-\mu$ m-thick formalinfixed, paraffin-embedded tissue sections in a pressure cooker using DAKO retrieval solution (for CD138), or 10-mM citrate, pH 6.0 (for CD38) (Zymed, South San Francisco, California). Following incubation in a hydrated chamber for one hour, the 


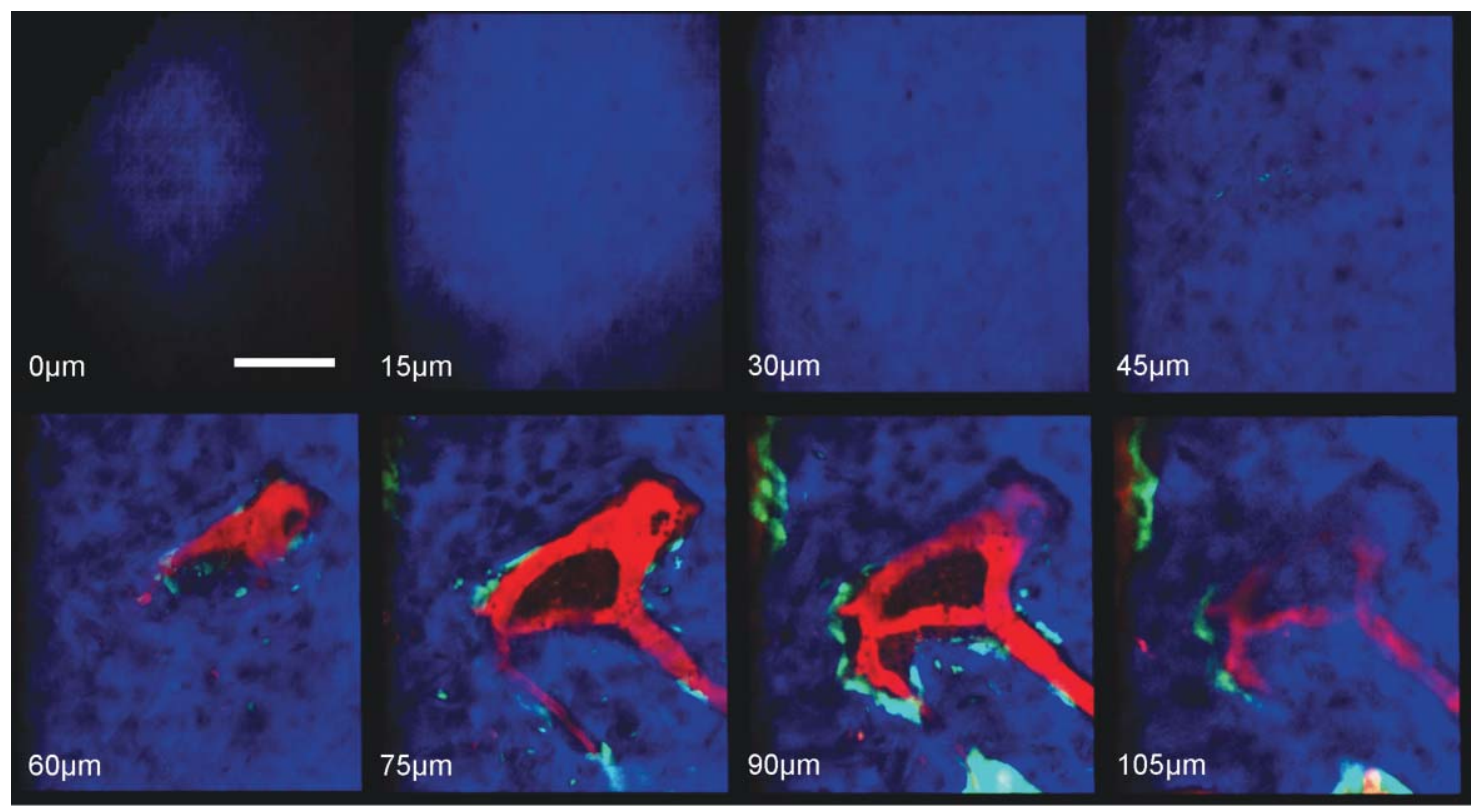

Fig. 1 Architecture of the normal bone marrow cavity. Selected images from a 3-D stack taken with second harmonic generation microscopy (bone, collagen: blue) and two-photon excited fluorescence (osteoblasts, GFP: green and vasculature, quantum dots: red). Shown here are every 15 th image from an original stack acquired with 1- $\mu \mathrm{m} \mathrm{z} \mathrm{step.} \mathrm{The} \mathrm{appearance} \mathrm{of} \mathrm{vasculature} \mathrm{within} \mathrm{a} \mathrm{small} \mathrm{bone} \mathrm{marrow} \mathrm{cavity} \mathrm{and} \mathrm{osteoblasts} \mathrm{lining} \mathrm{the} \mathrm{cavity}$ wall can be seen beginning at approximately $60 \mu \mathrm{m}$ below the bone surface. Scale bar equals $100 \mu \mathrm{m}$. (Color online only.)

primary antibodies were detected with the mouse Envision ${ }^{+}$ kit (for CD38; CD138, DAKO). Immunostaining was visualized with DAB chromogen (DAKO). All stained sections were also counterstained with hematoxylin prior to evaluation by a hematopathologist (Rodig) in a blinded fashion.

\section{Results}

\subsection{Normal Vascular/Endosteal Compartment in Bone Marrow}

Initially, we imaged normal mouse skull $\mathrm{BM}$ in Col2.3 mice (Fig. 1). These reporter mice were genetically engineered to express GFP under the osteoblast-lineage-restricted collagen $1 \alpha$ promoter. ${ }^{53}$ Osteoblasts are known to reside intermittently along the inner surface of the BM cavity (the endosteal surface) where bone remodeling occurs. ${ }^{56}$ We used second harmonic imaging to detect the collagen signal inherent in structural bone and two photon-excited fluorescence to detect the osteoblast-GFP and blood pool-quantum dot signals. As Fig. 1 demonstrates, we were able to image through the bone to the BM sinusoidal vasculature and endosteal cavity, the roof of which appeared around $60 \mu \mathrm{m}$ below the surface of the skull. The last frame in this figure demonstrates that the compartment extended to $105 \mu \mathrm{m}$ below the skull surface for this small cavity. All subsequent BM images in this work were taken between 50 and $200 \mu \mathrm{m}$ below the bone surface.

\subsection{Trafficking of Circulating Multiple Myeloma Cells to the Bone Marrow}

Within minutes after injection, MM cells could be seen interacting with the endothelium of the calvarial bone marrow vasculature by intravital confocal microscopy [Fig. 2(a)]. In the real-time video (available online) taken $90 \mathrm{~min}$ after injection of $3 \times 10^{6}$ cells, some cells have firmly attached to the endothelial wall while others briefly attached before returning to the circulation, and still others remained in the circulation without interacting with the vascular wall. The arrows in Fig. 2(a) follow the course of a single rolling MM cell.

In-vivo flow cytometry was used to quantify the number of circulating tumor cells as a function of time after cell injection. We have previously shown in this mouse xenograft model that after the first hour, the MM.1S cell number was reduced to approximately $20 \%$ of the original injected cell number. ${ }^{35}$ To confirm that the behavior of the MM.1S cell line in circulation was representative of malignant $\mathrm{MM}$ cells, we isolated cells based on the MM CD138 ${ }^{+}$phenotype from MM patient bone marrow biopsies, and subjected them to in-vivo flow cytometry. Figure 2(b) shows that the MM.1S cell line homing behavior is similar to that of MM patient samples. Previously, we have shown that clearance of the MM cells from the circulation was dependent on the CXCR4/SDF-1 interaction ${ }^{35}$ and was not the result of nonspecific interactions or MM cell trapping.

Others have shown that the VLA 4 integrin is important in homing and binding of stem cells to bone marrow endothelium, and that the process is completed through VLA 4 activation by SDF-1. Antibodies to VLA 4 inhibit stem cell migration through bone marrow endothelial cells. ${ }^{37}$ Therefore, to test the role of VLA 4 in the bone marrow trafficking of MM cells that express high levels of this molecule on the cell surface, ${ }^{58}$ we treated MM.1S cells with neutralizing anti-VLA 4 antibody before injecting cells into mice and performing in-vivo flow cytometry. Treatment with the antibody greatly increased the number of MM cells remaining in circulation after one hour compared to the number in control mice [Fig. 2(c)], further demonstrating that the numbers of circulating MM cells detected by in-vivo flow cytometry are inversely correlated with the homing potential of the MM cells. 


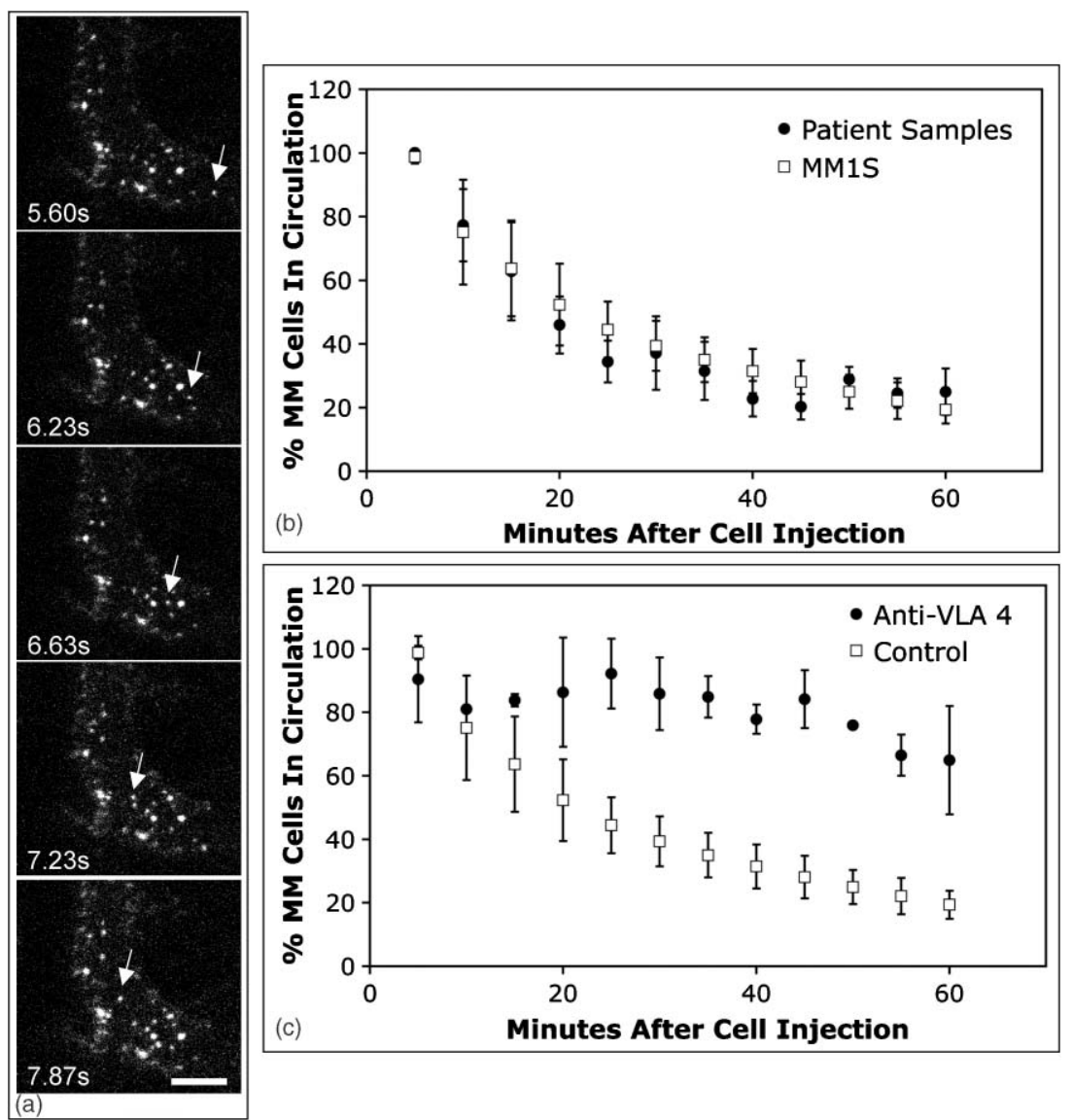

Fig. 2 Early homing of MM cells to the bone marrow is swift, as detected by in-vivo flow cytometry or in-vivo confocal microscopy. (a) Still frames from a video showing MM.1S cells roll and stick to the bone marrow vasculature. DiD-fluorescently stained MM.1S cells were injected into the mouse vasculature. $90 \mathrm{~min}$ after cell injection, the skull bone marrow was imaged. The panels in (a) are of the same area of the BM vasculature taken over time (indicated in the lower left corners of each frame). Many cells had already stuck to the endothelial surface. The arrows follow an MM.1S cell as it rolled along the vasculature. Scale bar equals $100 \mu \mathrm{m}$. (b) Depletion of CD138+ patient cells from the circulation occurs with the same kinetics as MM.1S cells. MM.1S $(n=4)$ or MM patient sample cells $(n=5)$ were labeled with fluorescent cytoplasmic or membrane dyes, injected into mice, and immediately the proportion of cells remaining in the circulation was measured by in-vivo flow cytometry and plotted against time. (c) Injected MM.1S cells are dramatically depleted from the circulation within an hour of injection unless homing is abrogated by treatment with an agent that interferes with binding through the CXCR4/SDF-1 pathway, such as anti-VLA 4 antibody (control $n=4$; VLA 4 treated $n=2$ ). (MOV, 11.5 MB) [URL: http://dx.doi.org/10.1117/1.3520571.1]

To better identify the sites of extravasation of the MM cells and spatial distribution in the bone marrow, we imaged Col2.3 mice that had been injected with DiD-labeled MM.1S cells. In these intravital images, as in Fig. 1, the vasculature is surrounded by bone, the surface of which is intermittently coated with osteoblasts. To identify the preferred homing sites for MM cells, we injected a much lower number of MM cells $\left(10^{5}\right)$ and followed these for three days. Figure 3 shows images of the injected cells in Col2.3 calvarial BM at 2 [Fig. 3(a)], 6 [Fig. 3(c)], and 72 [Fig. 3(d)] h post-injection. The MM.1S cells were found closely associated with the BM vasculature. 3-D analysis of $z$ stacks allowed us to determine the distance between myeloma cells and BM microstructures. Distance measurements taken at six hours post cell injection showed that most MM.1S cells could be found within $15 \mu \mathrm{m}$ of a blood vessel, compared to the distance between MM cells and the nearest osteoblast, which were as far as $120 \mu \mathrm{m}$ away [Fig. 3(b)]. We found that the myeloma cells continued to remain closely associated with the vasculature over the first three days [Figs. 3(c) and 3(d), and data not shown]. Similarly, injected cells from an isolated patient sample were found in the regions corresponding to the perisagittal areas in mouse calvarial bone $72 \mathrm{~h}$ after injection [Fig. 3(e)].

\subsection{Engraftment and Disease Progression}

For long-term tumor cell growth and development, we injected SCID/Bg mice with MM.1S cells that carried retroviral constructs for GFP and luciferase genes (MM.1S-GFP-Luc-neo cell line), allowing us to follow the tumors locally using fluorescence confocal microscopy, in whole animals using bioluminescence, and in the circulation using in-vivo flow cytometry. To investigate MM engraftment under normal BM conditions, we used mice that had not been irradiated prior to MM cell injection. This allowed imaging of unaltered bone marrow infrastructure, avoiding the irradiation-induced destruction of the resident stem and progenitor cells. To delineate the location of MM cells in relation to blood vessels, fluorescent labeling with the blood pool marker Angiosense was performed at serial time points during 

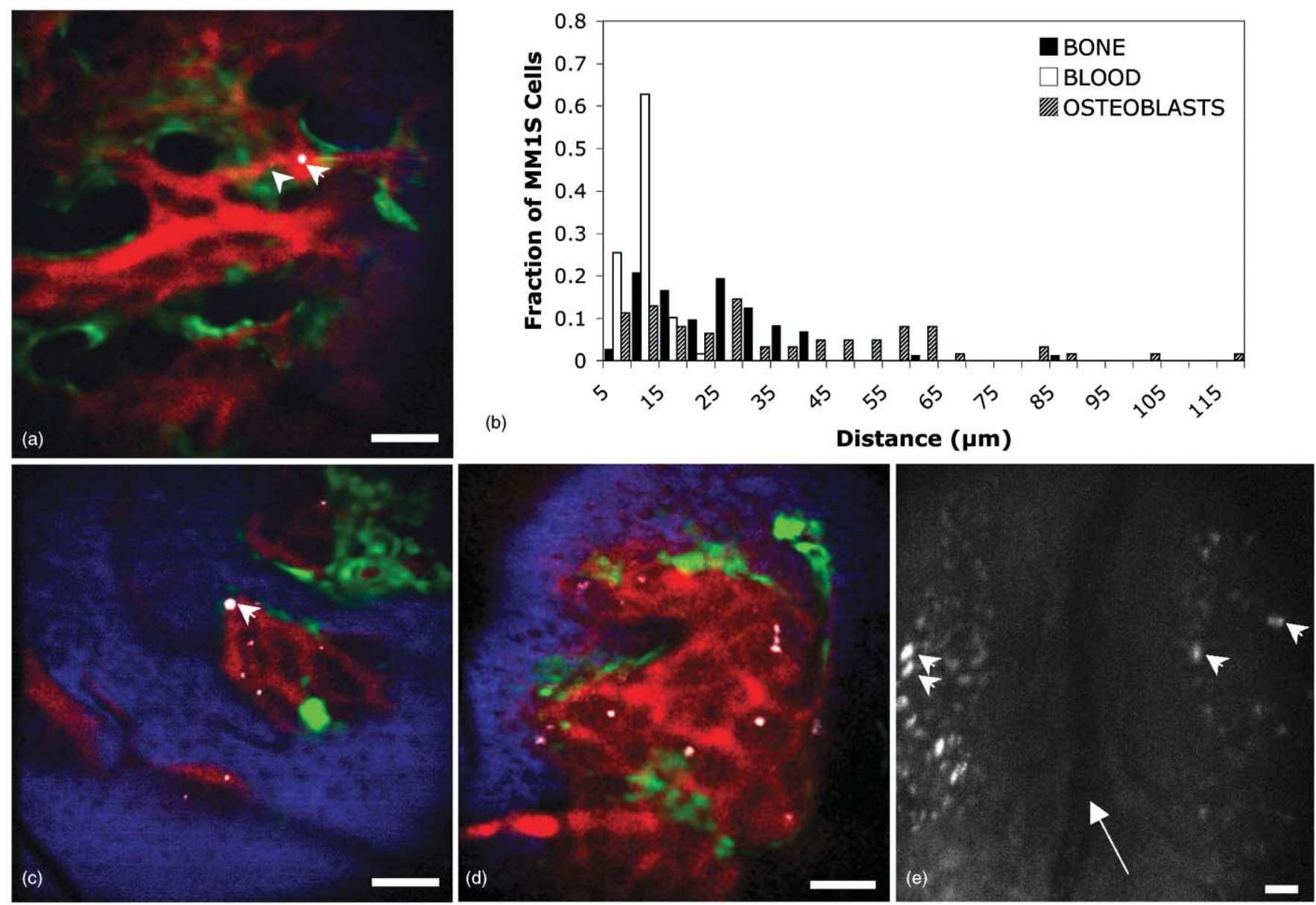

Fig. 3 Very early after injection, the MM cells position themselves in proximity to the vasculature. (a) DiD stained MM.1S cells were injected intravenously into Col2.3-GFP mice at a dose of 100,000 cells per mouse. Immediately before imaging, the mice were injected with the vascular marker Quantum Dots 800. The mice were imaged within 2-h (a), 6-h (c), and 72-h (d) post-MM cell injection. Images (a), (c), and (d) demonstrate the relationship of the MM cells (white) to the vasculature (red), osteoblasts (green) and bone (blue) during the first $72 \mathrm{~h}$ after cell injection. Arrowheads in (a) and (c) point to representative MM cells. (b) $Z$ stacks were acquired from multiple regions in the calvaria of the mice. Distances were measured and tabulated between MM cells and osteoblasts or endosteal surface for the first $6 \mathrm{~h}$ after MM cell injection. (e) CD138 ${ }^{+}$patient tumor cells were purified, stained with DiD, and injected into a SCID/Bg mouse. 72-h post-CD138 ${ }^{+}$cell injection, fluorescently labeled MM cells (arrowheads) could be found in the perisagittal regions along the central vessels (arrow). Less bright cells in the same regions are endogenous autofluorescent cells. Scale bars equal $100 \mu \mathrm{m}$. (Color online only.)

tumor progression. At four days post-injection, we observed single cells as well as small clusters of $\mathrm{GFP}^{+}$MM cells within vascular beds [Fig. 4(a)]. Although the entire skull was imaged for the presence of $\mathrm{GFP}^{+}$cells in the $x$ and $y$ planes as well as serially (sectioning through $200 \mu \mathrm{m}$ ) at each $x$ - $y$ position, we could only find a few regions of $\mathrm{GFP}^{+} \mathrm{MM}$ cells at early times post-injection. Eight and 14 days after the cells were injected, limited numbers of MM clusters were still closely associated with the vasculature [Figs. 4(b) and 4(c)]. By the third week, however, the tumor cells had expanded to take up significant areas of the localized sinusoidal bone marrow [Figs. 5(a) and 5(b)]. Large area montage images of median skulls are shown in Fig. 5, demonstrating the relationship between the central vessels, sinusoidal vasculature, and expanding myeloma population. Individual myeloma cells (short arrows) were detected in association with the vasculature hundreds of micrometers away from the tumor-dense areas. In the fifth week, however, plasmacytomas filled some of the sinusoids in the calvarial bone
[Fig. 6(a)], and expansion occurred along the sinusoidal vasculature (Fig. 6(b)]. In addition, MM cells associated closely with the central vein and artery [Fig. 6(c)]. Plasma cell infiltrate of the marrow was confirmed by histologic preparation of the same mouse calvarium [Fig. 6(d)], which stained positive for the plasma cell markers CD38 and CD138 [Figs. 6(e) and 6(f), respectively].

Bioluminescence images acquired at the 5-week time point indicated that in addition to the skull, tumor was growing in the vertebral column [Figs. 6(g) and 6(i)], as well as pelvis and femurs [Figs. 6(h) and 6(j)]. The pattern of tumor growth is similar to the human disease, which if left untreated, is marked by the spread of MM cells to the BM of the pelvis, femurs, vertebral column, and skull. ${ }^{19,25}$

In human patients, MM cells can also be found in the circulation as the tumors are established. ${ }^{23,41}$ To enumerate MM cells in mouse circulation during disease progression, we used noninvasive in-vivo flow cytometry ${ }^{55}$ to detect the number of 

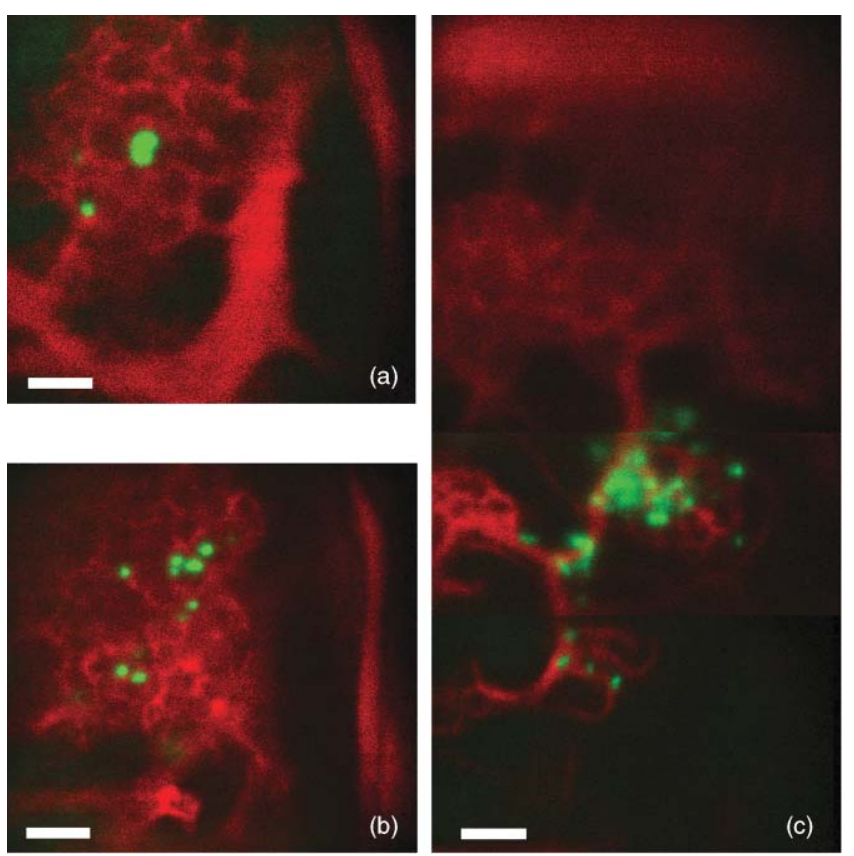

Fig. 4 Engraftment of $M M$ cells in the calvarial sinusoids. (a) Image taken of MM.1S cells in the skull bone marrow sinusoidal vasculature four days after the cells were injected. (b) Expanding MM.1S cells eight days after the MM.1S cells were injected. (c) Growth of the MM cells around the vasculature at day 14. Red indicates blood pool, Angiosense labeling; green defines GFP ${ }^{+}$MM.1S cells. Scale bars equal $100 \mu \mathrm{m}$. (Color online only.)

$\mathrm{GFP}^{+}$cells flowing through an ear arteriole over time. Figure 7 (solid line) shows the increase in circulating cell number during the first six weeks of tumor progression.

\subsection{Response to the Therapeutic Agent Bortezomib}

To monitor response to bortezomib treatment in vivo in the SCID/Bg MM model, we began treatment twice weekly when tumors became visible using BLI. After three $1-\mathrm{mg} / \mathrm{kg}$ bortezomib treatments, the tumor size decreased, as shown in the BLI images [Figs. 8(g) and 8(h) vs. Figs. 8(e) and 8(f)], and the number of circulating MM cells also decreased (Fig. 7, dashed line) as determined by in-vivo flow cytometry. When the tumor burden fell below the BLI detection level, a small number of remaining MM cells were still clearly evident by confocal imaging [Figs. 8(d) vs. 8(c)]. Even more dramatically, the number of areas in the calvarial BM where MM cells could be found decreased after bortezomib [Figs. 8(b) vs. 8(a)]. At this point, several areas of treated calvarial bone contained only one or few MM cells [Fig. 8(d)]. These results clearly indicate the potential for use of the increased sensitivity of in-vivo confocal microscopy in following tumor treatment and detection of residual tumor cells post-therapy in cancer models.

\section{Discussion}

In this work, we have successfully followed the initiation and development of MM in vivo, as well as its response to therapy, in a xenograft model using a combination of complementary in vivo imaging and flow cytometry modalities. Growth of tumors was imaged using MM.1S cells carrying GFP and luciferase constructs in nonirradiated SCID/Bg mice. The presence of the GFP and luciferase genes allowed us to image using both in-vivo fluorescence confocal microscopy and bioluminescence imaging to detect limited numbers and positions of tumor cells at early time points, and follow the bulk tumor burden at later time points. In addition, shed tumor cells in the circulation were detected using in-vivo flow cytometry. The SCID/Bg genetic background alleviated the need to irradiate the mice to obtain successful engraftment of the human tumor cells because these mice are defective in mature B, T, and NK cells. ${ }^{59}$ Elimination of this step avoided the toxic and inflammatory effects of irradiation on the bone marrow, and provided a more faithful environment to host the MM cells and recapitulate the human disease. As SCID/Bg mice carry mutations that occur late in leukocyte differentiation that specifically block development of mature B, T, and NK cells, the bone marrow mileu retains the normal early hematopoietic and mesenchymal progenitors, as well as mature mesenchymal cells that would normally be encountered by MM cells. Numerous studies have pointed out the role the BM microenvironment plays in the growth of $\mathrm{MM},{ }^{47}$ a component of disease models that is altered by irradiation. Presumably all successful tumor growth occurs because the tumors circumvent the immune system. While using this model to artificially avoid some interaction of the tumor cells with mature immune cells, we have, more importantly, avoided the broader damage to the bone marrow microenvironment induced by irradiation. Our purpose was not to investigate the interactions between the tumor and the immune system, but to follow and characterize tumor growth using in-vivo imaging and flow cytometry modalities in a model that possessed characteristics of the human disease. By using the techniques presented here and appropriate reporter mice, one could follow the development of mouse malignancies in syngeneic animals. That our xenograft model possessed characteristics of the human disease was demonstrated by the BLI data showing involvement of hips, femurs, vertebrae, ribs, and skull [Figs. 6(g) through 6(j), and the in-vivo flow cytometry data demonstrating increased circulating tumor cell numbers with disease progression (Fig. 7). Use of noninvasive in-vivo flow cytometry allowed us to follow circulating cells in the same mice repeatedly throughout the study, both during tumor growth and in response to therapy. In addition, we were able to demonstrate that the MM.IS cell line behaved like freshly isolated human myeloma samples with respect to homing [Figs. 2(b) and 3(e)].

This study provides the first insight into the localization of MM cells within the BM microenvironment when few MM cells are present that could be missed by standard biopsies and immunohistochemistry. Our data suggest a close association of MM cells with the BM vasculature. Early MM cell division and migration appeared to occur along the vasculature (Fig. 4). By three weeks post-MM cell injection, individual MM cells were seen in the sinusoidal regions of the calvarium, hundreds of micrometers away from the tumor bed [Figs. 5(a) and 5(b)]. Consistently, MM cells were found closely associated with normal marrow vasculature in regions adjacent to marrow spaces completely infiltrated with tumor [Fig. 6(a) and 6(b)]. Since MM cells were also found in the peripheral circulation (Fig. 7), association with the vasculature may be critical for the dissemination of the disease. It has long been accepted that cancer metastases 

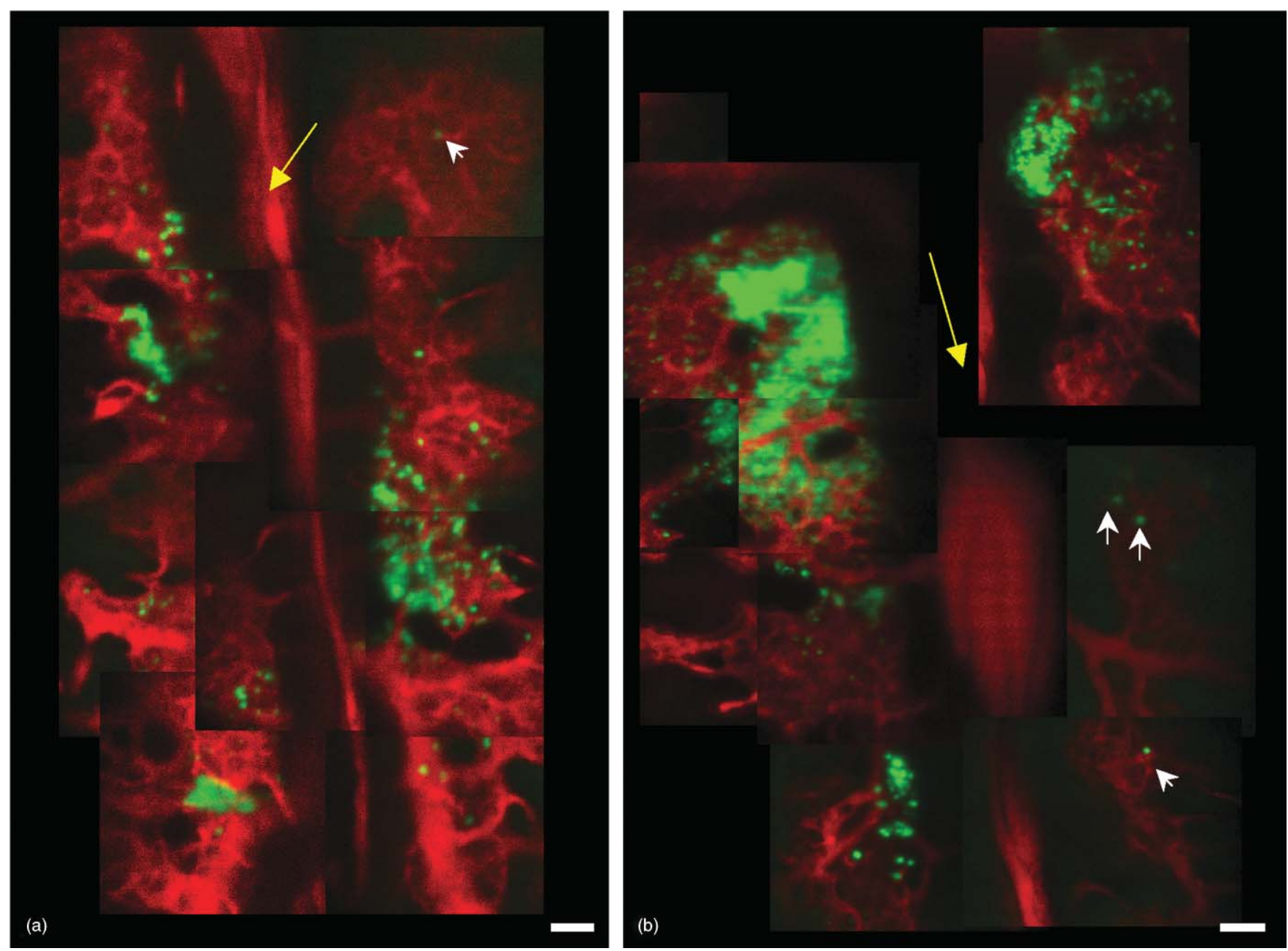

Fig. 5 Plasmacytomas are evident in the calvaria by the third week. Mosaics of individual fields of view imaged by confocal microscopy show that at days (a) 20 and (b) 22 post-MM.1S cell injection, confocal imaging detects the formation of plasmacytomas in the BM sinusoids. Individual MM cells exist away from the bulk of the tumors (short arrows). Long arrows indicate the positions of the central arteries and veins under the metopic sutures of these mice. Scale bars equal $100 \mu \mathrm{m}$. (Color online only.)

involve dissemination of tumor cells through the vasculature ${ }^{60,61}$ or lymphatic system. ${ }^{62}$

The interaction of MM and its bone marrow microenvironment has been implicated in resistance to therapy. ${ }^{47,63}$ The interactions between myeloma cells and bone marrow components such as osteoclasts ${ }^{64}$ and plasmacytoid dendritic cells ${ }^{65}$ have been documented. Previous studies have indicated that MM disease results in down-regulation of osteoblast activity. This effect appears to be the result of an inhibition of osteoblastogenesis $^{38-40}$ through direct cell-cell interaction between MM cells and osteoblast progenitors, as well as through soluble factors. At very early time points post-injection, we saw no overt interaction between the MM cells and BM osteoblasts [Figs. 3(a), 3(b), and 3(c)]. This is different from normal hematopoietic stem/progenitor cells that home in close proximity to both the vasculature and endosteal surface immediately after injection. ${ }^{56}$ It is not clear whether inhibition of osteoblastogenesis occurs early during MM progression or is a late-stage phenomenon. Further work with reporter mice in conjunction with intravital microscopy will shed light on the interaction of $\mathrm{MM}$ and various components of the BM.
Use of in-vivo confocal and multiphoton microscopy, with its increased imaging sensitivity, and this xenograft mouse model will allow future studies of several central, but not mutually exclusive, questions relating to MM. Among these are the detection of cancer stem cells, detection of dormant cells, and detection of minimal residual disease after therapy.

Of critical importance to understanding and treating cancers is the issue of dormant and quiescent cells: cells that do not divide but remain viable and cells that divide at a slower rate than the bulk of the tumor population, respectively. Many blood cancers and some epithelial cancers have been demonstrated to contain populations of cells with different division and disease transmission capabilities. Most cells in the tumor mass have finite division capability and cannot transmit the disease at all or transmit it at a much lower efficiency than the cancer stem cells. ${ }^{66}$ For MM, it has been reported that a small cancer stem cell population of $\mathrm{CD} 138^{-} / \mathrm{CD} 20^{+}$cells exists. ${ }^{67}$ In our MM xenograft model, the mice were injected with unsorted MM.1S cells, which contained largely CD138 ${ }^{+}$cells and a much smaller population of $\mathrm{CD}^{-138^{-}}$cells. It will be interesting to image sorted $\mathrm{CD} 138^{+}$vs. $\mathrm{CD}^{-} 38^{-}$populations to 

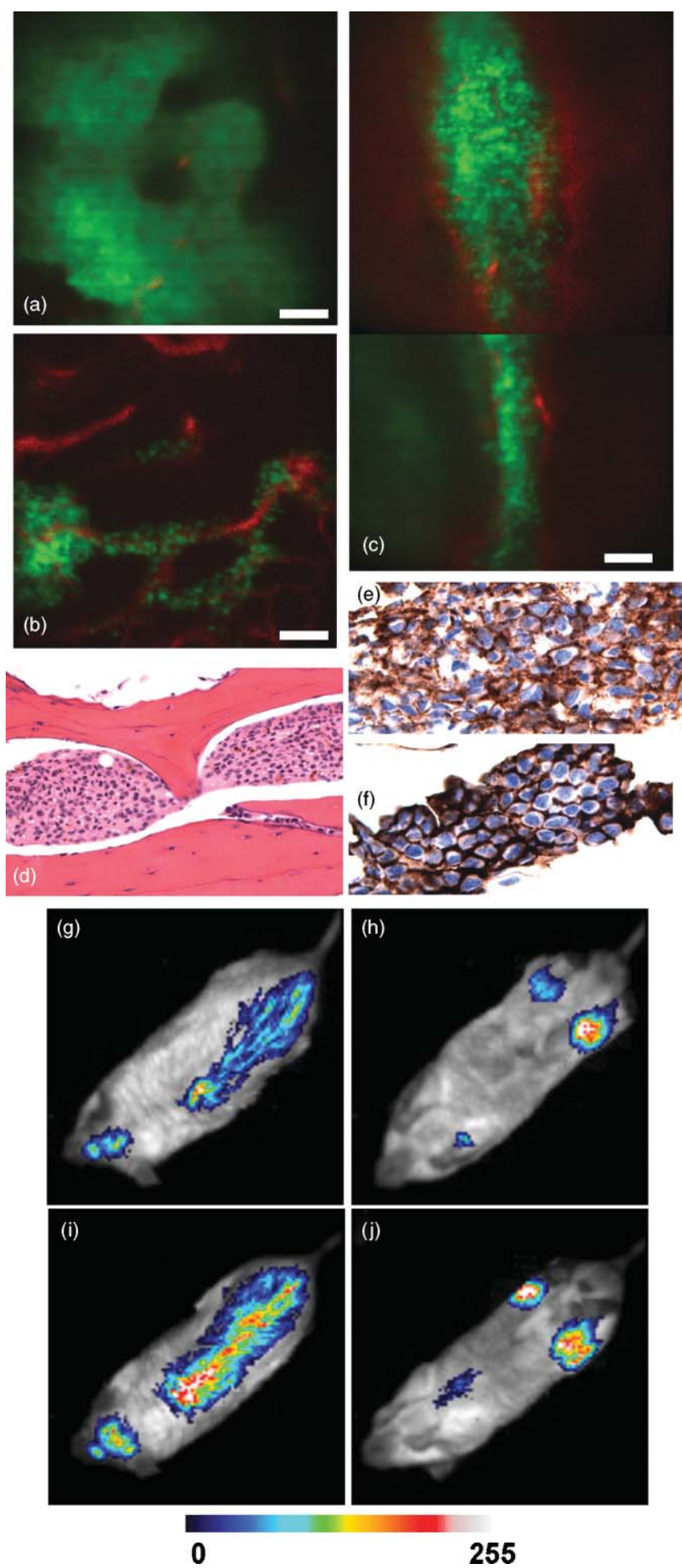

0

Fig. 6 In the fifth week, tumors are detected by immunohistochemistry, confocal microscopy, and BLI. (a), (b), and (c) are confocal images, that reveal tumor that has filled sinusoidal regions (a), grown along the central artery and vein (c), and continued along more distal vessels (b). Scale bars equal $100 \mu \mathrm{m}$. Immunohistochemistry of the calvarium of the same mouse as in (a), (b), and (c) shows massive tumor infiltrate (d) that stained positively for (e) CD38 and (f) CD138. Original magnification in (d), (e), and (f) was $400 \times$. Bioluminescence images of ventral and dorsal views of two representative mice showing (g) and (i) skull and vertebral involvement; and hip, femur, and rib involvement in (h) and (j). Color bar indicates the relative luminescence intensity. (Color online only.)

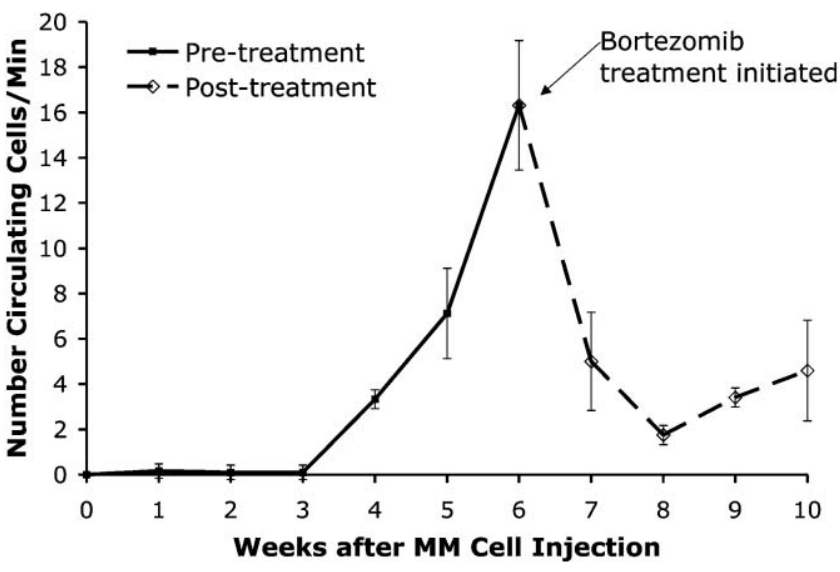

Fig. 7 The number of circulating MM cells is an accurate measure of tumor burden. Weekly in-vivo flow cytometry was repeatedly performed on mice that had been injected with MM.1S-GFP-Luc-neo cells. The number of $\mathrm{GFP}^{+}$cells were counted and plotted against time. Beginning in the sixth week post cell injection, bortezomib was administered twice-weekly as is given clinically. Solid line indicates cell counts accumulated before the mice were treated. Dashed line indicates cell counts after twice-weekly bortezomib treatment. For each data point, $n=3$.

assess whether there are differences in BM localization, growth potential, and sensitivity to therapy. Furthermore, imaging of various transgenic reporter mice marked for BM cell types will address the issue of specific niche requirements for MM stem cell engraftment.

Metastases that appear years after the primary event are attributed to the presence of re-awakened dormant cells. Studies of breast cancer patients revealed frequent appearance of disseminated cancer cells in the $\mathrm{BM}^{68}$ and other nontumor-bearing organs, ${ }^{69}$ and the presence of carcinoma cells in bone marrow indicated a poor outcome for the patient. ${ }^{68}$ These cells may take years to form metastases, if at all. In addition to their role in metastasis, dormant and quiescent cells survive cytotoxic treatments, ${ }^{70}$ suggesting a role for them in minimal residual disease.

Whether the returning tumor is the result of a specific cancer cell (i.e., cancer stem cell or dormant cell), cell survival due to quiescence or its auspicious placement in its microenvironment, or some combination of these is a matter to be addressed by technologies that can detect small numbers of malignant cells. Our data point out the existence of single cells and clusters of cells surviving therapy [Fig. 8(d)], as well as detection of single MM cells as the cells engrafted and grew (Figs. 3, 4, and 5). Future work using tumor cells either expressing a cell cycle marker or retaining labeling probes (to detect quiescent cells in vivo) will address whether specific interaction with BM elements can enhance survival of the malignant cells after therapy.

Thus far, this model system is limited by the restriction that only the relatively flat-surfaced calvarial bone can be imaged with minimal invasiveness. Further improvements to this system that allow imaging of MM tumor growth in the long bones are ongoing. In addition, continuous monitoring of the same mice for tumor growth using confocal and multiphoton microscopy can be limited by scar tissue development, as a result of the surgical procedure to expose the surface of the skull bone, resulting in impaired visualization of the bone marrow. Methods to reduce scar formation are also under development. 

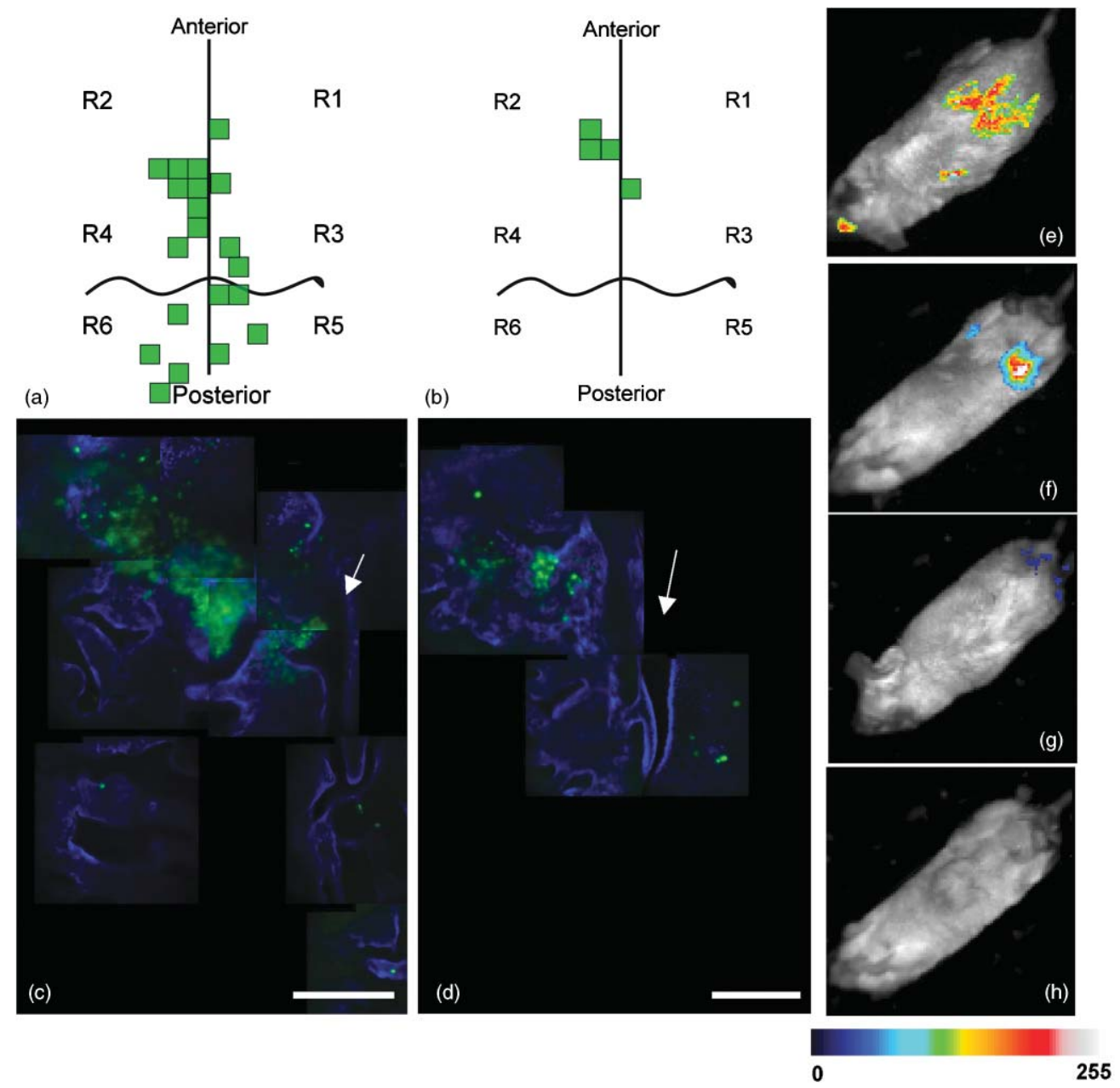

Fig. 8 In-vivo confocal imaging detects surviving cells after therapy. Throughout this experiment, diagrammatic maps were made of GFP+ MM sites in the calvaria of mice at selected times after the MM.1S-GFP-Luc-neo cells were injected. Detection of GFP ${ }^{+}$MM cells was done in $x, y$, and $z$ planes. (a) and (b) Representative map of GFP + MM sites from a mouse (b) after three bortezomib treatments and (a) a control untreated mouse at the same time point. Vertical line represents the central vein and artery; wavy horizontal line represents the coronal suture. For mapping purposes, each skull was divided into six regions (R numbers). Mosaics of images of the fields of view corresponding to maps (a) and (b) are shown in (c) and (d), respectively. For (c) and (d), the endosteum was delineated with osteosense, a fluorescent bisphosphonate that binds to hydroxyapatite at the bone surface (blue). Scale bars equals $400 \mu \mathrm{m}$ for (c) and (d). Representative bioluminesence images of mice (g) and (h) treated with three bortezomib doses or (e) and (f) not treated. Color bar indicates the relative luminescence intensity. (Color online only.)

In summary, we have described the combined use of in-vivo microscopy, in-vivo flow cytometry, and BLI to document the malignant progression in live animals at multiple spatial and temporal scales. These technologies facilitate the delineation of the mechanisms and mediators of homing, adhesion, and egress of tumor cells from the BM milleu. They further enable the detection and sampling of human myeloma cells growing in xenograft models to assess the growth, survival, and drug resistance mechanisms induced by tumor cell interaction with the BM microenvironment. Most importantly, advances in in-vivo imaging studies as described here can provide critical validation of promising novel treatment strategies to overcome adhesionmediated drug resistance and improve patient outcome.

\section{Acknowledgments}

We wish to thank David Rowe for providing the Col2.3 mice, Christina LoCelso for maintaining the colony of mice, and Daniel Côté for providing the image capture software, iPho- ton. This work was supported by NIH R01 CA125690, R01 CA133799, and P50 CA086355.

\section{References}

1. D. R. Welch, "Technical considerations for studying cancer metastasis in vivo," Clin. Exp. Metastasis 15(3), 272-306 (1997).

2. T. Wilson and J. W. Hastings, "Bioluminescence," Ann. Rev. Cell Dev. Biol. 14, 197-230 (1998).

3. J. Y. Adams, M. Johnson, M. Sato, F. Berger, S. S. Gambhir, M. Carey, M. L. Iruela-Arispe, and $\mathrm{L}$. Wu, "Visualization of advanced human prostate cancer lesions in living mice by a targeted gene transfer vector and optical imaging," Nat. Med. 8(8), 891-897 (2002).

4. S. Bhaumik and S. S. Gambhir, "Optical imaging of Renilla luciferase reporter gene expression in living mice," Proc. Natl. Acad. Sci. USA 99(1), 377-382 (2002).

5. C. H. Contag, D. Jenkins, P. R. Contag, and R. S. Negrin, "Use of reporter genes for optical measurements of neoplastic disease in vivo," Neoplasia 2(1-2), 41-52 (2000).

6. M. Edinger, Y. A. Cao, M. R. Verneris, M. H. Bachman, C. H. Contag, and R. S. Negrin, "Revealing lymphoma growth and the efficacy of 
immune cell therapies using in vivo bioluminescence imaging," Blood 101(2), 640-648 (2003).

7. A. Wetterwald, G. Van Der Pluijm, I. Que, B. Sijmons, J. Buijs, M. Karperien, C. W. Lowik, E. Gautschi, G. N. Thalmann, and M. G. Cecchini, "Optical imaging of cancer metastasis to bone marrow: a mouse model of minimal residual disease," Am. J. Pathol. 160(3), 1143-1153 (2002).

8. M. Vooijs, J. Jonkers, S. Lyons, and A. Berns, "Noninvasive imaging of spontaneous retinoblastoma pathway-dependent tumors in mice," Cancer Res. 62(6), 1862-1867 (2002).

9. D. E. Jenkins, Y. Oei, Y. S. Hornig, S. F. Yu, J. Dusich, T. Purchio, and P. R. Contag, "Bioluminescent imaging (BLI) to improve and refine traditional murine models of tumor growth and metastasis," Clin. Exp. Metastasis 20(8), 733-744 (2003).

10. J. W. Kang, P. Kim, C. A. Alonzo, H. Park, and S. H. Yun, "Two-photon microscopy by wavelength-swept pulses delivered through single-mode fiber," Opt. Lett. 35(2), 181-183 (2010).

11. P. Kim, E Chung, H. Yamashita, K. E. Hung, A. Mizoguchi, R Kucherlapati, D. Fukumura, R. K. Jain, and S. H. Yun, "In vivo wide-area cellular imaging by side-view endomicroscopy," Nat. Meth. 7(4), 303-305 (2010).

12. I. B. Mazo and U. H. von Andrian, "Adhesion and homing of bloodborne cells in bone marrow microvessels," J. Leukoc. Biol. 66(1), 25-32 (1999).

13. J. S. Condeelis, J. Wyckoff, and J. E. Segall, "Imaging of cancer invasion and metastasis using green fluorescent protein," Eur. J. Cancer 36(13), 1671-1680 (2000).

14. A. F. Chambers, I. C. MacDonald, E. E. Schmidt, V. L. Morris, and A. C. Groom, "Preclinical assessment of anticancer therapeutic strategies using in vivo videomicroscopy," Cancer Metastasis. Rev. 17(3), 263-269 (1998-1999).

15. G. N. Naumov, S. M. Wilson, I. C. MacDonald, E. E. Schmidt, V. L. Morris, A. C. Groom, R. M. Hoffman, and A. F. Chambers, "Cellular expression of green fluorescent protein, coupled with high-resolution in vivo videomicroscopy, to monitor steps in tumor metastasis," J. Cell. Sci. 112(12), 1835-1842 (1999).

16. J. Condeelis and J. E. Segall, "Intravital imaging of cell movement in tumors," Nat. Rev. Cancer 3(12), 921-930 (2003).

17. R. K. Jain, "Understanding barriers to drug delivery: high resolution in vivo imaging is key," Clin. Cancer Res. 5(7), 1605-1606 (1999).

18. R. M. Hoffman, "Visualization of GFP-expressing tumors and metastasis in vivo," Biotech. 30(5), 1016-1026 (2001).

19. E. D. George and R. Sadovsky, "Multiple myeloma: recognition and management," Am. Fam. Phys. 59(7), 1885-1894 (1999).

20. R. A. Kyle, T. M. Therneau, S. V. Rajkumar, D. R. Larson, M. F. Plevak, and L. J. Melton, 3rd, "Incidence of multiple myeloma in Olmstead County, Minnesota: trend over six decades," Cancer 101(11), 2667-2674 (2004)

21. L. W. Terstappen, S. Johnsen, I. M. Segers-Nolten, and M. R. Loken, "Identification and characterization of plasma cells in normal human bone marrow by high-resolution flow cytometry," Blood 76(9), 1739-1747 (1990).

22. R. A. Kyle and S. V. Rajkumar, "Multiple myeloma," N. Engl. J. Med. 351(18), 1860-1873 (2004).

23. D. Billadeau, B. Van Ness, T. Kimlinger, R. A. Kyle, T. M. Therneau, P. R. Greipp, and T. E. Witzig, "Clonal circulating cells are common in plasma cell proliferative disorders: a comparison of monoclonal gammopathy of undetermined significance, smoldering multiple myeloma, and active myeloma," Blood 88(1), 289-296 (1996).

24. S. Kumar, S. V. Rajkumar, R. A. Kyle, M. Q. Lacy, A. Dispenzieri, R. Fonseca, J. A. Lust, M. A. Gertz, P. R. Greipp, and T. E. Witzig, "Prognostic value of circulating plasma cells in monoclonal gammopathy of undetermined significance," J. Clin. Oncol. 23(24), 5668-5674 (2005).

25. P. Tassone, P. Neri, D. R. Carrasco, R. Burger, V. S. Goldmacher, R. Fram, V. Munshi, M. A. Shammas, L. Catley, G. S. Jacob, S. Venuta, K. C. Anderson, and N. C. Munshi, "A clinically relevant SCID-hu in vivo model of human multiple myeloma," Blood 106(2), 713-716 (2005).

26. M. Urashima, B P. Chen, S. Chen, G. S. Pinkus, R. T. Bronson, D. A. Dedera, Y. Hoshi, G. Teoh, A. Ogata, S. P. Treon, D. Chauhan, and K. C. Anderson, "The development of a model for the homing of mul- tiple myeloma cells to human bone marrow," Blood 90(2), 754-765, (1997).

27. R. LeBlanc, L. P. Catley, T. Hideshima, S. Lentsch, C. S. Mitsiades, N. Mitsiades, D. Neuberg, O. Goloubeva, C. S. Pien, J. Adams, D. Gupta, P. G. Richardson, N. C. Munshi, and K. C. Anderson, "Proteosome inhibitor PS-341 inhibits human myeloma cell growth in vivo and prolongs survival in a murine model," Cancer Res. 62(17), 4996-5000 (2002).

28. C. S. Mitsiades, N. S. Mitsiades, R. T. Bronson, D. Chauhan, N. Munshi, S. P. Treon, C. A. Maxwell, L Pilarski, T. Hideshima, R. M. Hoffman, and K. C. Anderson, "Fluorescence imaging of multiple myeloma cells in a clinically relevant SCID/NOD in vivo model: biologic and clinical implications," Cancer Res. 63(20), 6689-6696 (2003).

29. C. S. Mitsiades, K. C. Anderson, and D. R. Carrasco, "Mouse models of human myeloma," Hematol. Oncol. Clin. North Am. 21(6), 10511069(viii) (2007)

30. D. A. Sipkins, X. Wei, J. W. Wu, J. M. Runnels, D. Côté, T. K. Means, A. D. Luster, D. T. Scadden, and C. P. Lin, "In vivo imaging of specialized bone marrow endothelial microdomains for tumour engraftment," Nature 435(7044), 969-973 (2005).

31. A. Müller, B. Homey, H. Soto, N. Ge, D. Catron, M. E. Buchanan, T. McClanahan, E. Murphy, W. Yuan, S. N. Wagner, J. L. Berrera, A. Mohar, E. Verástegui, and A. Zlotnik, "Involvement of chemokine receptors in breast cancer metastasis," Nature 410 (6824), 50-56 (2001).

32. M. Takenaga, H. Tamamura, K. Hiramatsu, N. Nakamura, Y. Yamaguchi, A. Kitagawa, S. Kawai, H. Nakashima, N. Fujii, and R. Igarashi, "A single treatment with microcapsules containing CXCR4 antagonist suppresses pulmonary metastasis of murine melanoma," Biochem. Biophys. Res. Commun. 320(1), 226-232 (2004).

33. A. Peled, I Petit, O. Kollet, M. Magid, T. Ponomaryov, T. Byk, A. Nagler, H. Ben-Hur, A. Many, L. Shultz, O. Lider, R. Alon, D. Zipori, and T. Lapidot, "Dependence of human stem cell engraftment and repopulation of NOD/SCID mice on CXCR4," Science 283(5403), 845-848 (1999).

34. T. Lapidot and O. Kollet, "The essential roles of the chemokine SDF-1 and its receptor CXCR4 in the human stem cell homing and repopulation of transplanted immune-deficient NOD/SCID and NOD/SCID/B2m(null) mice," Leukemia 16(10), 1992-2003 (2002).

35. Y. Alsayed, H. Ngo, J. Runnels, X. Leleu, U. K. Singha, C. M. Pitsillides, J. A. Spencer, T. Kimlinger, J. M. Ghobrial, X. Jia, G. Lu, M. Timm, A. Kumar, D. Côté, I. Veilleux, K. E. Hedin, G. D. Roodman, T. E. Witzig, A. L. Kung, T. Hideshima, K. C. Anderson, C. P. Lin, and I. M. Ghobrial, "Mechanisms of regulation of CXCR4/SDF-1 (CXCL12)dependent migration and homing in multiple myeloma," Blood 109(7), 2708-2717 (2007).

36. A. K. Azab, J. M. Runnels, C. Pitsillides, A. S. Moreau, F. Azab, X. Leleu, X. Jia R. Wright, B. Ospina, A. L. Carlson, C. Alt, N. Burwick, A. M. Roccaro, H. T. Ngo, M. Farag, M. R. Melhem, A. Sacco, N. C. Munshi, T. Hideshima, B. J. Rollins, K. C. Anderson, A. L. Kung, C. P. Lin, and I. M. Ghobrial, "The CXCR4 inhibitor AMD3100 disrupts the interaction of multiple myeloma cells with the bone marrow microenvironment and enhances their sensitivity to therapy," Blood 113(18), 4341-4351 (2009).

37. A. Peled, O. Kollet, T. Ponomaryov, I. Petit, S. Franitza, V. Grabovsky, M. M. Slav, A. Nagler, O. Lider, R. Alon, D. Zipori, and T. Lapidot, "The chemokine SDF-1 activates the integrins LFA-1, VLA-4, and VLA-5 on immature human $\mathrm{CD} 34(+)$ cells: role in transendothelial/stromal migration and engraftment of NOD/SCID mice," Blood 95(11), 32893296 (2000).

38. E. Tian, F. Zhan, R. Walker, E. Rasmussen, Y. Ma, B. Barlogie, and J. D. Shaughnessy, Jr., "The role of Wnt-signaling antagonist DKK1 in the development of osteolytic lesions in multiple myeloma," N. Eng. J. Med. 349(26), 2483-2494 (2003).

39. L. A. Ehrlich, H. Y. Chung, I. Ghobrial, S. J. Choi, F. Morandi, S. Colla, V. Rizzoli, G. D. Roodman, and N. Giuliani, "IL-3 is a potential inhibitor of osteoblast differentiation in multiple myeloma," Blood 106(4), 1407-1414 (2005).

40. T. Standal, N. Abildgaard, U. M. Fagerli, B. Stordal, O. Hjertner, M. Borset, and A. Sundan, "HGF inhibits BMP-induced osteoblastogenesis: possible implications for the bone disease of multiple myeloma," Blood 109(7), 3024-3030 (2006). 
41. C. K. Lee, E. S. K. Ma, T. W. H. Shek, C. C. K. Lam, W. Y. Au, T. S. K. Wan, and L. C. Chan, "Plasmablastic transformation of multiple myeloma," Hum. Pathol. 34(7), 710-714 (2003).

42. H. Brenner, A. Gondos, and D. Pulte, "Recent major improvements in long-term survival of younger patients with multiple myeloma," Blood 111(5), 2521-2526 (2008).

43. S. K. Kumar, S. V. Rajkumar, A. Dispenzieri, M. Q. Lacy, S. R. Hayman, F. K. Buadi, S. R. Zeldenrust, D. Dingli, S. J. Russell, J. A. Lust, P. R. Greipp, R. A. Kyle, and M. A. Gertz, "Improved survival in multiple myeloma and the impact of novel therapies," Blood 111(5), 2516-2520 (2008).

44. T. Hideshima, P. Richardson, D. Chauhan, V. J. Palombells, P. J. Elliott, J. Adams, and K. C. Anderson, "The proteosome inhibitor PS-341 inhibits growth, induces apoptosis, and overcomes drug resistance in human multiple myeloma cell lines," Cancer Res. 61(7), 3071-3076 (2001).

45. T. Hayashi, T. Hideshima, M. Akiyama, K. Podar, H. Yasui, N. Raje, S. Kumar,. D. Chauhan, S. P. Treon, P. Richardson, and K. C. Anderson, "Molecular mechanisms whereby immunomodulatory drugs activate natural killer cells: clinical application," Br. J. Haematol. 128(2), 192-203 (2005).

46. S. Kumar, N. Raje, T. Hideshima, K. Ishitsuka, A. Roccaro, N. Shiraishi, M. Hamasaki, H. Yasui, N. C. Munshi, P. Richardson, W. D. Figg, and K. C. Andersn, "Antimyeloma activity of two novel N-substituted and tetrafluorinated thalidomide analogs," Leukemia 19(7), 1253-1261 (2005).

47. K. C. Anderson, "Targeted therapy of multiple myeloma based upon tumor-microenvironmental interactions," Exp. Hematol. 35(4 Suppl 1), $155-162$ (2007).

48. J. Adams, "Development of the proteasome inhibitor PS-341," Oncologist 7(1), 9-16 (2002).

49. S. Thomas, T. Richards, and D. M. Weber, "Novel Agents for Previously Untreated Multiple Myeloma," Chap. 8 in Multiple Myeloma: Translational and Emerging Therapies. K. C. Anderson, and I. M. Ghobrial, Eds., pp. 141-167, Informa Healthcare USA Inc., New York (2008).

50. A. L. Goldberg, "Protein degradation and protection against misfolded or damaged proteins," Nature 426(6968), 895-899 (2003).

51. H. C. Drexler, "Activation of cell death program by inhibition of proteasome function," Proc. Natl. Acad. Sci. 94(3), 855-860 (1997).

52. J. Delic, P. Masdehors, S. Omura, J. M. Cosset, J. Dumont, J. L. Binet, and H. Magdelénat, "The proteasome inhibitor lactacystin induces apoptosis and sensitizes chemo- and radioresistant human chronic lymphocytic leukaemia lymphocytes to TNF-alpha-initiatedapoptosis," Br. J. Cancer 77(7), 1103-1107 (1998).

53. Z. Kalajzic, P. Liu, I. Kalajzic, Z. Du, A. Braut, M. Mina, E. Canalis, and D. W. Rowe, "Directing the expression of a green fluorescent protein transgene in differentiated osteoblasts: comparison between rat type I collagen and rat osteocalcin promoters," Bone 31(6), 654-660 (2002).

54. R. E. Goldman-Leiken, H. R. Salwen, C. V. Herst, D. Variakojis, M. L. Bian, M. M. Le Beau, P. Selvanayagan, R. Marder, R. Anderson, S. Weitzman, and S. T. Rosen, "Characterization of a novel myeloma cell line, MM.1," J. Lab. Clin. Med. 113(3), 335-345, (1989).
55. J. Novak, I. Georgakoudi, X. Wei, A. Prossin, and C. P. Lin, "In vivo flow cytometer for real-time detection and quantification of circulating cells," Opt. Lett. 29(1), 77-79 (2004).

56. C. Lo Celso, H. E. Fleming, J. W. Wu, C. X. Zhao, S Miake-Lye, J. Fujisaki, D. Côté, D. W. Rowe, C. P. Lin, and D. T. Scadden, "Liveanimal tracking of individual haematopoietic stem/progenitor cells in their niche," Nature 457(7225), 92-96 (2009).

57. A. Ascenzi and C. Fabry, "Technique for dissection and measurement of refractive index of osteones," J. Biophys. Biochemic. Cytol. 6(1), 139-142 (1959).

58. H. Uchiyama, B. A. Barut, D. Chauhan, S. A. Cannistra, and K. C. Anderson, "Characterization of adhesion molecules on human myeloma cell lines," Blood 80(9), 2306-2314 (1992).

59. J. R. MacDougall, B. A. Croy, C. Chapeau, and D. A. Clark, "Demonstration of a splenic cytotoxic effector cell in mice of genotype SCID/SCID.BG/BG," Cell Immunol. 130(1), 106-117 (1990).

60. J. Folkman, "Seminars in Medicine of the Beth Isreal Hospital, Boston. Clinical applications of research on angiogenesis," N. Engl. J. Med. 333(26), 1757-1763 (1995).

61. S. Paget, "The distribution of secondary growths in cancer of the breast. 1889," (republication of Paget's 1889 Lancet article). Cancer Metastsis Rev. 8(2), 98-101 (1989).

62. M. A. Swartz, M. Skobe, "Lymphatic function, lymphangiogenesis, and cancer metastasis," Microsc. Res. Tech. 55(2), 92-97 (2001).

63. T. Hideshima, C. Mitsiades, G. Tonon, P. G. Richardson, and K. C. Anderson, "Understanding multiple myeloma pathogenesis in the bone marrow to identify new targets," Nat. Rev. Cancer 7(8), 585-598 (2007).

64. G. D. Roodman, "Novel targets for myeloma bone disease," Expert Opin. Ther. Targets 12(11), 1377-1387 (2008).

65. D. Chauhan, A. V., Singh, M. Brahmandam, R. Carrasco, M. Bandi, T. Hideshima, G. Bianchi, K. Podar, YT. Tai, C. Mitsiades, N. Raje, D. L. Jaye. S. K. Kumar, P. Richardson, N. Munshi, and K. C. Anderson, "Functional interaction of plasmacytoid dendritic cells with multiple myeloma cells: a therapeutic target," Cancer Cell 16(4), 309-323 (2009).

66. J. E. Dick, "Stem cell concepts renew cancer research," Blood 112(13), 4793-4807 (2008).

67. W. Matsui, C. A. Huff, Q. Wang, M. T. Malehorn, J. Barber, Y. Tanhehco, B. D. Smith, C. I. Civin, and R. J. Jones, "Characterization of clonogenic multiple myeloma cells," Blood 103(6), 2332-2336 (2004).

68. S. Riethdorf, H. Wikman, and K. Pantel, "Review: Biological relevance of disseminated tumor cells in cancer patients," Int. J. Cancer 123(9), 1991-2006 (2008).

69. M. Suzuki, E. S. Mose, V. Montel, and D. Tarin, "Dormant cancer cells retrieved from metastasis-free organs regain tumorigenic and metastatic potency," Am. J. Pathol. 169(2), 673-681 (2006).

70. G. N. Naumov, J. L. Townson, I. C. MacDonald, S. M. Wilson, V. H. Bramwell, A. C. Groom, and A. F. Chambers, "Ineffectiveness of doxorubicin treatment on solitary dormant mammary carcinoma cells or late-developing metastases," Breast Cancer Res. Treat. 82(3), 199-206 (2003). 